\title{
$\beta$-Actin and Fascin-2 Cooperate to Maintain Stereocilia Length
}

\author{
Benjamin J. Perrin, ${ }^{1}$ Dana M. Strandjord, ${ }^{1}$ Praveena Narayanan, ${ }^{1}$ Davin M. Henderson, ${ }^{1}$ Kenneth R. Johnson, ${ }^{2}$ \\ and James M. Ervasti ${ }^{1}$ \\ ${ }^{1}$ Departments of Biochemistry, Molecular Biology, and Biophysics, University of Minnesota, Minneapolis, Minnesota 55455, and 2The Jackson Laboratory, \\ Bar Harbor, Maine 04609
}

Stereocilia are actin-based protrusions on auditory sensory hair cells that are deflected by sound waves to initiate the conversion of mechanical energy to neuronal signals. Stereocilia maintenance is essential because auditory hair cells are not renewed in mammals. This process requires both $\beta$-actin and $\gamma$-actin as knock-out mice lacking either isoform develop distinct stereocilia pathology during aging. In addition, stereocilia integrity may hinge on immobilizing actin, which outside of a small region at stereocilia tips turns over with a very slow, months-long half-life. Here, we establish that $\beta$-actin and the actin crosslinking protein fascin- 2 cooperate to maintain stereocilia length and auditory function. We observed that mice expressing mutant fascin- 2 (p.R109H) or mice lacking $\beta$-actin share a common phenotype including progressive, high-frequency hearing loss together with shortening of a defined subset of stereocilia in the hair cell bundle. Fascin- 2 binds $\beta$-actin and $\gamma$-actin filaments with similar affinity in vitro and fascin- 2 does not depend on $\beta$-actin for localization in vivo. Nevertheless, double-mutant mice lacking $\beta$-actin and expressing fascin-2 p.R109H have a more severe phenotype suggesting that each protein has a different function in a common stereocilia maintenance pathway. Because the fascin-2 p.R109H mutant binds but fails to efficiently crosslink actin filaments, we propose that fascin-2 crosslinks function to slow actin depolymerization at stereocilia tips to maintain stereocilia length.

\section{Introduction}

Stereocilia are protrusions formed from crosslinked actin filaments on the apical surfaces of mechanosensitive auditory and vestibular hair cells. On each hair cell, several stereocilia are organized into a bundle with tiered rows whose lengths are precisely regulated so that associated mechanotransduction channels are synchronously gated by mechanical stimulation. In addition to precise length regulation, stereocilia must also be effectively maintained because mammalian auditory hair cells are not renewed.

Stereocilia length maintenance and durability may depend on minimizing actin turnover. In contrast to actin in related cellular structures, such as microvilli, where filaments are rapidly turned over by treadmilling (Loomis et al., 2003), stereocilia actin is very stable. Recent measurements demonstrated that actin along the length of stereocilia has a months-long half-life, whereas only the tips feature more rapid actin turnover (Zhang et al., 2012). Ste-

Received Jan. 17, 2013; revised Feb. 25, 2013; accepted March 23, 2013.

Author contributions: B.J.P., D.M.S., K.R.J., and J.M.E. designed research; B.J.P., D.M.S., and P.N. performed research; D.M.H. and K.R.J. contributed unpublished reagents/analytic tools; B.J.P., D.M.S., and J.M.E. analyzed data; B.J.P. wrote the paper.

This work was supported by NIH Grants R01AR049899 to J.M.E., R01DC005827 to K.R.J., and R03DC12354 to B.J.P. Parts of this work were performed in the Characterization Facility, University of Minnesota, a member of the National Science Foundation-funded Materials Research Facilities Network (www.mrfn.org) via the Materials Research Science and Engineering Centers program.

The authors declare no competing financial interests

Correspondence should be addressed to Dr. Benjamin J. Perrin, University of Minnesota, 6-155 Jackson Hall, 321 Church Street Southeast, Minneapolis, MN 55455. E-mail: perrin@umn.edu.

DOI:10.1523/JNEUROSCI.0238-13.2013

Copyright $\odot 2013$ the authors $\quad 0270-6474 / 13 / 338114-08 \$ 15.00 / 0$ reocilia stability additionally depends on tip links, which are heterodimers of cadherin-23 and protocadherin-15 that connect adjacent stereocilia and gate the mechanotransduction channel (Kazmierczak et al., 2007). Tip-link loss during development causes rows 2 and 3 of the stereocilia bundle to shorten, suggesting that the tip links or the associated mechanotransduction activity regulate actin stability (Caberlotto et al., 2011b). Tip links may also play a role in stereocilia stability during adulthood as the $C d h 23^{\text {ahl }}$ allele, which encodes a short variant of cadherin-23, contributes to age-related hearing loss (AHL) in several inbred mouse strains (Noben-Trauth et al., 2003).

$C d h 23^{a h l}$ homozygosity is often required for other AHL genes to show a phenotype, further suggesting that tip links are an upstream regulator of stereocilia stability. For example, DBA/2J mice express a mutant fascin-2 R109H protein and develop rapidly progressing high-frequency loss during early adulthood, which is suppressed by the full-length $C d h 23^{+}$allele (Johnson et al., 2008; Shin et al., 2010). Based on similarity to fascin-1 (Lin-Jones and Burnside, 2007), fascin-2 (fascin homolog 2; encoded by Fscn2) is a monomeric globular protein with two actinbinding sites that may stabilize stereocilia by crosslinking adjacent filaments (Sedeh et al., 2010; Jansen et al., 2011).

Finally, stereocilia stability also depends on the actin isoform composition as demonstrated by distinct phenotypes of actin knock-out mice. $\gamma$-Actin knock-out mice lose hearing across the frequency spectrum, whereas $\beta$-actin knock-outs more resemble hearing loss in DBA/2J mice with earlier loss of high-frequency hearing. Stereocilia pathology is also different in each actin knock-out. Ablating $\gamma$-actin results in the loss of individual 
members of the hair cell bundle, whereas $\beta$-actin knockout leads to shortening of the second and third rows of the auditory hair cell bundle (Perrin et al., 2010).

Here, we report that fascin-2 p.R109H fails to efficiently crosslink actin and stereocilia expressing this mutant fascin-2 share a similar phenotype with $\beta$-actin knock-out stereocilia. Although fascin-2 does not preferentially interact with $\beta$-actin over $\gamma$-actin, the double-mutant mouse lacking $\beta$-actin and expressing fascin-2 p.R109H loses high-frequency hearing more rapidly than singly mutant mice while displaying morphologically similar stereocilia degradation. Together these data suggest a model where fascin- 2 and $\beta$-actin together regulate actin dynamics to prevent stereocilia shortening.

\section{Materials and Methods}

Mice. Mice of either sex were used. Genotyping procedures and mice bearing the $A c t g 1^{\text {flox }}\left(A c t g 1^{\text {tm1.2Erv }}\right)$ and $A c t b^{\text {flox }}\left(A c t b^{\text {tm1.1Erv }}\right)$ alleles, the Cdh $23^{+}$allele on an otherwise C57BL/6J background (B6.CAST$C d h 23^{A h l+} / \mathrm{Kjn}$, The Jackson Laboratory stock no. 002756) as well as the Atoh-cre (Tg(Atoh1-cre)Bfri) and CAG-cre/ESR1 [Tg(CAG-cre/ ESR ${ }^{\star}$ )5Amc] transgenes were previously described (Hayashi and McMahon, 2002; Keithley et al., 2004; Matei et al., 2005; Perrin et al., 2010; Bunnell et al., 2011). The Cdh23 allele was confirmed by Sanger sequencing. Except for mice used in Figure 1, where the Cdh23 allele is indicated, all mice are on a congenic C57BL/6 genetic background homozygous for the $C d h 23^{\text {ahl }}$ allele. The C57BL/6J (B6) subcongenic line with the DBA/ 2J-derived R109H Fscn 2 mutation was developed by first crossing mice of the B6.D2-Chr11D/LusJ congenic strain (Davis et al., 2005) with B6 mice. The hybrid progeny from this cross were then mated with B6 mice, and the resulting backcross progeny were genotyped for five DNA microsatellite markers spanning the introgressed region of the B6.D2Chr11D/LusJ congenic strain. Backcross mice that were homozygous for B6 alleles at markers D11Mit90, D11Mit360, D11Mit338, and D11Mit203, and heterozygous for B6 and DBA/2J alleles at D11Mit104 were selected and interbred. The progeny from these matings were genotyped and those that were confirmed to be homozygous for B6 alleles at D11Mit90 (70.5 Mb position of Chr 11, GRCm38), D11Mit360 (103.4 $\mathrm{Mb}$ ), D11Mit338 (115.5 Mb), and D11Mit203 (116.4 Mb), and homozygous for DBA/2J alleles at D11Mit104 (119.3) and Fscn2 (120.4 Mb) were interbred to produce the homozygous subcongenic line designated B6.D2-Fscn $2^{\text {ahls }} / 4 \mathrm{Kjn}$, which is publicly available from The Jackson Laboratory (stock no. 9629) and is referred to in the text as B6.D2$F s c n 2^{R 109 H}$. Standard mouse husbandry practices were used to generate the other indicated lines. Animals were housed and treated in accordance with the standards set by the University of Minnesota Institutional Animal Care and Use Committee.

Scanning electron microscopy. Cochlea were fixed in $2.5 \%$ glutaraldehyde in $0.1 \mathrm{M}$ sodium cacodylate buffer with $1 \mathrm{~mm} \mathrm{CaCl}_{2}$ by perfusing dissected cochlea through the round and oval windows followed by incubation in the same solution at room temperature for $4 \mathrm{~h}$. After decalcification in $170 \mathrm{~mm}$ EDTA at $4^{\circ} \mathrm{C}$ for $16 \mathrm{~h}$, the organ of Corti was dissected. Tissue was successively incubated in $2 \%$ each arginine, glycine, glutamic acid, and sucrose in water, $2 \%$ each tannic acid and guanidine- $\mathrm{HCl}$ in water, and then $1 \%$ osmium tetroxide. Samples were critical point dried from $\mathrm{CO}_{2}$ and sputter-coated with platinum before viewing on a cold field emission scanning electron microscope (Hitachi S4700). Stereocilia were measured using ImageJ software and statistical analysis (Student's $t$ test) was performed using GraphPad Prism software.

Antibodies. Polyclonal antibodies against fascin-1 and fascin-2 were made in rabbits using full-length Flag-tagged protein as antigen. Each antibody was affinity purified from serum using antigen bound to nitrocellulose, eluted with glycine, $\mathrm{pH} 2.7$, neutralized with Tris- $\mathrm{HCl}, \mathrm{pH} 8.0$, and conjugated to Alexa-568 fluorescent dye using a monoclonal antibody labeling kit (Invitrogen) following the manufacturer's instructions. Dye-conjugated anti- $\gamma$-actin (clone $1-37$ ) anti- $\beta$-actin antibodies (clone AC-15, Abcam) were as previously described (Perrin et al., 2010).
Auditory brainstem response. Auditory brainstem response (ABR) waveforms were collected as previously described (Belyantseva et al., 2009) for frequencies between $4 \mathrm{kHz}$ and $32 \mathrm{kHz}$ at half-octave intervals, starting at suprathreshold levels and decreasing in $5 \mathrm{~dB}$ steps to a subthreshold level. A Tucker-Davis Technologies System 3 was used to generate symmetrically shaped tone bursts $1 \mathrm{~ms}$ in duration with $300 \mu \mathrm{s}$ raised cosine ramps that were delivered to a calibrated magnetic speaker. Mice were anesthetized with avertin and scalp potentials were recorded with subdermal electrodes with signals amplified 20,000 times, bandpass filtered between 0.03 and $10 \mathrm{kHz}$, digitized using a 20,000 $\mathrm{kHz}$ sampling rate and subjected to artifact rejection. Stacked waveforms were compared and the lowest level of stimulation that evoked an unambiguous ABR waveform was designated as the threshold.

Immunofluorescent microscopy. Adult mice were perfused with $4 \%$ paraformaldehyde (PFA) in PBS, cochlea were dissected, a small hole was made in the apex, the round and oval windows were removed and then cochlea were incubated in fixative solution for $2 \mathrm{~h}$ at room temperature. Cochlea were washed in PBS and then decalcified in $170 \mathrm{~mm}$ EDTA in PBS at $4^{\circ} \mathrm{C}$ for $16 \mathrm{~h}$. The organ of Corti was dissected, postfixed in $100 \%$ methanol at $-20^{\circ} \mathrm{C}$ for $10 \mathrm{~min}$, rinsed in PBS and permeabilized in $0.5 \%$ Triton X-100 in PBS for $20 \mathrm{~min}$ at room temperature. Tissue was blocked for $1 \mathrm{~h}$ in $5 \%$ goat serum in PBS before incubation with the indicated antibodies. Samples were mounted in ProLong anti-fade reagent (Invitrogen) and viewed on a Deltavision PersonalDV microscope equipped with a $100 \times 1.4$ NA objective (Applied Precision). Stacks of images were collected at $0.20 \mu \mathrm{m}$ intervals and subsequently deconvolved using Resolve3D software (Applied Precision). To quantify the ratio of fascin-2 to $\gamma$-actin, samples were immunostained in parallel and imaged using identical exposure settings. Fluorescent intensities were measured along the length of 5-10 well oriented stereocilia per cell using the line tool in Resolve3D software (Applied Precision), averaged, and the normalized ratio of fascin-2 to $\gamma$-actin was calculated.

Immunoblot analysis. Cochlea were dissected from mice of the indicated genotypes, frozen in liquid nitrogen, ground into powder, and resuspended in 1\% SDS in PBS. Fibroblasts from mice that were hemizygous for the CAG-cre/ESR1 transgene, and homozygous for either $A c t b^{f l o x}$ or $A c t g 1^{f l o x}$ were treated with tamoxifen as previously described (Bunnell et al., 2011) and scraped into the same buffer. Samples were boiled, centrifuged to remove insoluble material, and protein concentration in the resulting lysate was determined by $\mathrm{A}_{280}$ measurement. Equal amounts of protein were separated by SDS-PAGE, transferred to nitrocellulose membranes, and probed with the indicated antibodies. Fluorescently labeled secondary antibodies were detected and quantified using an Odyssey infrared scanner and software (Li-Cor Biosciences).

Fascin-2 expression and purification. A mouse Fscn 2 cDNA clone was purchased from ImaGene (clone no. IRCLp5011C0424D), amplified by PCR with primers to add an N-terminal Flag tag (forward primer: CACC ATGGATTATAAGGATGACGATGACAAGGCCCCTGAAGCAACGTG GCT, reverse primer: GGCTCTGGGGTTGACCCCCT) and cloned into pENTR/D-TOPO (Invitrogen) following the manufacturer's instructions. The R109H mutation was introduced using the QuikChange mutagenesis kit (Stratagene). For expression in insect cells, the Flag-tagged construct was shuttled to pDEST8 (Invitrogen).

Constructs were transformed into DH10bac Escherichia coli (Invitrogen) to produce the recombinant bacmid, which was purified and used to transfect SF21 cells cultured in SF900 III media (Invitrogen). After viral amplification, infected cell pellets were lysed in PBS with protease inhibitors by sonication and centrifuged at 20,000 $\times g$. Flag-fascin- 2 protein was purified from the lysate by Flag-affinity chromatography using Flagantibody-conjugated beads (Sigma-Aldrich), eluted with Flag peptide, dialyzed into PBS, and centrifuged at $100,000 \times g$ for $30 \mathrm{~min}$ with soluble protein collected from the supernatant.

Actin isoform preparation. $\alpha$-Skeletal-actin and platelet nonmuscle actin were purchased from Cytoskeleton. $\gamma$-Actin was expressed in the Bac-to-Bac insect cell-expression system from Invitrogen. Mouse Actg1 cDNA was amplified by PCR and cloned into the p10 promoter of pFastbac Dual by restriction digest. No affinity tags were added. Insect cells were lysed in G-buffer ( $5 \mathrm{~mm}$ Tris, pH 8.0, $0.2 \mathrm{~mm} \mathrm{CaCl}_{2}$, and $0.2 \mathrm{~mm}$ ATP) by sonication and $\gamma$-actin was purified by DNase chromatography 


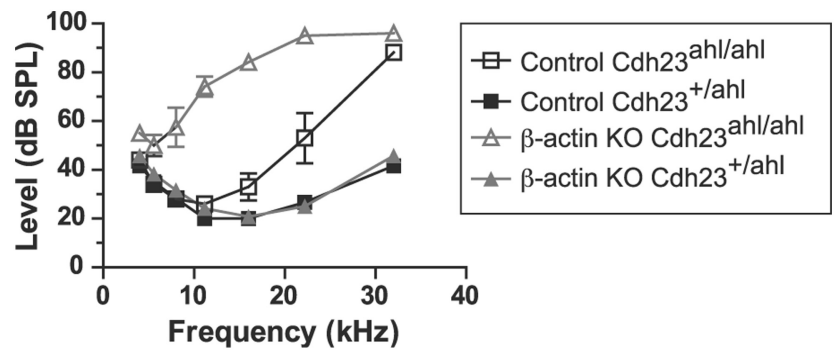

Figure 1. The $C \mathrm{dh}_{23} 3^{+}$allele suppresses hearing loss due to $\beta$-actin knockout. ABR thresholds were determined at the indicated frequencies for 6-month-old control mice ( $\mathrm{Cdh} 23^{+/ a h l}$ $\left.A c t b^{\text {flox/flox }}\right)$ or conditional $\beta$-actin knock-out mice $\left(\mathrm{Cdh} 23^{+/ a h l}\right.$ Act $b^{\text {flox/flox }}$ with Atoh1-cre transgene). For comparison, control and conditional $\beta$-actin knock-out C57BL/6J mice homozygous for $C \mathrm{dh} 23^{\text {ahl }}$ (Cdh23 ${ }^{\text {ahl/ahl }} A c t b^{\text {flox/flox }}$ with or without expression of Atoh1-cre) were replotted from (Perrin et al., 2010).

as previously described (Prochniewicz and Thomas, 1999). Briefly, the lysate was clarified by centrifugation for $20 \mathrm{~min}$ at $14,000 \times g$ and passed over a DNase column prepared from DNAseI (Roche) and affigel 10 active ester agarose (Bio-Rad) following the Bio-Rad coupling instructions. Actin was eluted from DNAseI with $50 \%$ formamide in G-buffer onto a $1 \mathrm{ml}$ of DEAE Sepharose (Sigma-Aldrich) column. The DEAE column was washed and eluted using $0.3 \mathrm{M} \mathrm{KCl}$. Actin was dialyzed into $500 \mathrm{ml}$ of G-buffer overnight, concentrated to $\sim 1 \mathrm{mg} / \mathrm{ml}$ and polymerized with $10 \times$ polymerization buffer $\left(500 \mathrm{~mm} \mathrm{KCL}, 20 \mathrm{mM} \mathrm{MgCl}_{2}\right.$ and 10 mM ATP). Polymerized actin was resuspended in $1 \times$ polymerization buffer and stored for experiments at $4^{\circ} \mathrm{C}$ for up to a week. Actins were polymerized in F-buffer ( $5 \mathrm{~mm}$ Tris- $\mathrm{HCl}, \mathrm{pH}$ 8.0, $0.2 \mathrm{mM} \mathrm{CaCl}_{2}, 50 \mathrm{~mm}$ $\mathrm{KCl}, 2 \mathrm{~mm} \mathrm{MgCl}_{2}, 0.2 \mathrm{~mm}$ ATP, and $0.5 \mathrm{~mm}$ DTT).

Actin cosedimentation. For the high-speed cosedimentation assay, Flag-fascin-2 or the p.R109H mutant (750 nM) was mixed with various concentrations of the indicated actin isoform (range 0.1-22 $\mu \mathrm{M}$ ) in F-buffer with $15 \mu \mathrm{M}$ phalloidin to stabilize F-actin. Each reaction was incubated at room temperature for $30 \mathrm{~min}$ and centrifuged at 100,000 $\times$ $g$ for $30 \mathrm{~min}$. For low-speed cosedimentation experiments, $500 \mathrm{~nm}$ Flagfascin- 2 was mixed with $5 \mu \mathrm{M} \alpha$-skeletal actin in PBS with $50 \mathrm{mM} \mathrm{KCl}$ and $2 \mathrm{mM} \mathrm{MgCl}_{2}$. Reactions were incubated for $30 \mathrm{~min}$ and then centrifuged at $18,000 \times g$ for $30 \mathrm{~min}$ at room temperature. Resulting supernatant and pellet fraction we subjected to SDS-PAGE, stained with Coomassie blue and scanned using a Licor Odyssey allowing quantification of supernatant and pellet fractions. At least three independent experiments were performed and nonlinear regression analysis was performed in GraphPad Prism software. The Kd \pm SE was determined from a fit of the aggregated data. To compare fascin- 2 binding to platelet or $\gamma$-actin, $\mathrm{Kd}$ values from individual experiments were analyzed using an unpaired Student's $t$ test.

$q P C R$. RNA was prepared from primary mouse embryonic fibroblasts cultured as previously described (Bunnell et al., 2011) with the Aurum Total RNA Mini Kit (Bio-Rad) according to the manufacturer's manual, quantified by $\mathrm{A}_{260}$ and reverse transcribed with the iScript Reverse Transcription Supermix for RT-qPCR (Bio-Rad). qPCR reactions were prepared with the SsoFast EvaGreen Supermix (Bio-Rad) and quantified on a MyiQ thermal cycler (Bio-Rad). Raw data were analyzed with Bio-Rad's accompanying software including calculation of threshold cycles $\left(\mathrm{C}_{\mathrm{t}}\right)$, normalization to reference genes $\left(\Delta \mathrm{C}_{\mathrm{t}}\right)$ and calculation of gene expression levels $\left(\Delta \Delta \mathrm{C}_{\mathrm{t}}\right)$. Relative gene expression data were $\log _{2}$ transformed, then the mean and SDs calculated. Significance of gene expression differences was determined by a one-sample, two-tailed $t$ test with significance threshold at $\alpha=0.05$. Primers were designed to detect the transcripts Actb (NM_007393.3), Actg1 (NM_009609.2), Fscn1 (NM_007984.2), and Fscn2 (NM_172802.4), as well as the reference control transcripts Hprt1 (NM_013556.2), and Ppia (NM_008907.1). Primers were generated with the Primer-BLAST software (http://www.ncbi. nlm.nih.gov/tools/primer-blast) to amplify across an exon junction.

\section{Results}

$\boldsymbol{\beta}$-Actin knock-out phenotype depends on cadherin-23

We previously demonstrated that hair cell-specific $\beta$-actin knock-out mice develop progressive hearing loss accompanied by shortening of auditory hair cell stereocilia (Perrin et al., 2010). The C57BL/6J (B6) mouse strain used in that study is predisposed to hearing loss due in part to $C d h 23^{\text {ahl }}$ homozygosity, which results in expression of a short variant of the tip-link component cadherin-23 (Noben-Trauth et al., 2003). Because the dominant acting full-length $\mathrm{Cdh}_{23^{+}}$allele suppresses many progressive hearing loss phenotypes (Noben-Trauth and Johnson, 2009), we assessed the relationship between cadherin-23 and $\beta$-actin by generating hair cell-specific $\beta$-actin knock-out mice heterozygous for $C d h 23^{+/ a h l}$ on an otherwise B6 background. ABRs were measured at 24 weeks of age. Consistent with previous reports, one copy of the wild-type $C d h 23^{+}$allele improved highfrequency hearing in B6 control mice (Fig. 1) (Keithley et al., 2004). In addition, a single copy of the $C d h 23^{+}$allele completely suppressed the progressive hearing loss caused by $\beta$-actin knockout, demonstrating a phenotypically relevant interaction between $\beta$-actin and cadherin-23 (Fig. 1). This result is in contrast to $\gamma$-actin knock-out mice, in which the $C d h 23$ genotype had no effect on hearing loss (Perrin et al., 2010).

\section{Stereocilia lengths are not maintained during aging in DBA/2J mice}

The DBA/2J inbred mouse strain develops age-related hearing loss due in part to a missense mutation in the Fscn2 gene (the Fscn $2^{\text {ahls }}$ allele, here more specifically designated $F_{s c n} 2^{R 109 H}$ ) that encodes fascin-2 p.R109H (Shin et al., 2010). Because fascin-2 is an abundantly expressed actin-binding protein in stereocilia (Shin et al., 2010, 2013), we compared the morphology of DBA/2J stereocilia bundles to stereocilia lacking either $\beta$-actin or $\gamma$-actin using scanning electron microscopy. In 5-week-old DBA/2J mice, outer hair cell $(\mathrm{OHC})$ bundles from the apical turn of the cochlea had normal morphology (Fig. $2 A$ ), whereas in the middle turn and basal turn the shorter rows of stereocilia in the bundle (rows $2-3$, where row 1 is the tallest row) were irregular and decreased in length (Fig. $2 B, C$ ). The more severe degradation of stereocilia in the basal turn is consistent with the initial onset of high-frequency hearing loss previously observed in the DBA/2J strain and the tonotopic organization of the cochlea (Johnson et al., 2008; Shin et al., 2010). Because hearing loss in DBA/2J mice is progressive, we also compared $\mathrm{OHC}$ and inner hair cell (IHC) stereocilia from the middle turn of 3- or 16-week-old DBA/2J mice. Although stereocilia heights were very uniform within each row of the bundle at 3 weeks of age, by 16 weeks of age individual stereocilia within rows 2 and 3 of the bundle were quite variable in height (Fig. 2D-I). Although the overall number of stereocilia per bundle was not different at either age, the average length of row 3 stereocilia was significantly shorter at 16 weeks of age (Fig. $2 J, K)$. Interestingly, row 1 , the tallest row in the bundle, is not affected with neighboring stereocilia of that row maintaining normal lengths (Fig. $2 D, G$ ). This phenotype is very similar to that of $\beta$-actin knock-out mice where stereocilia form normally, maintain normal numbers of stereocilia per bundle but develop shorter and irregular heights in rows 2 and 3 of the bundle as mice age (Fig. 2L) (Perrin et al., 2010). In contrast, stereocilia lacking $\gamma$-actin maintain normal length but individual stereocilia are lost from all rows of the bundle (Fig. 2M) (Perrin et al., 2010). 

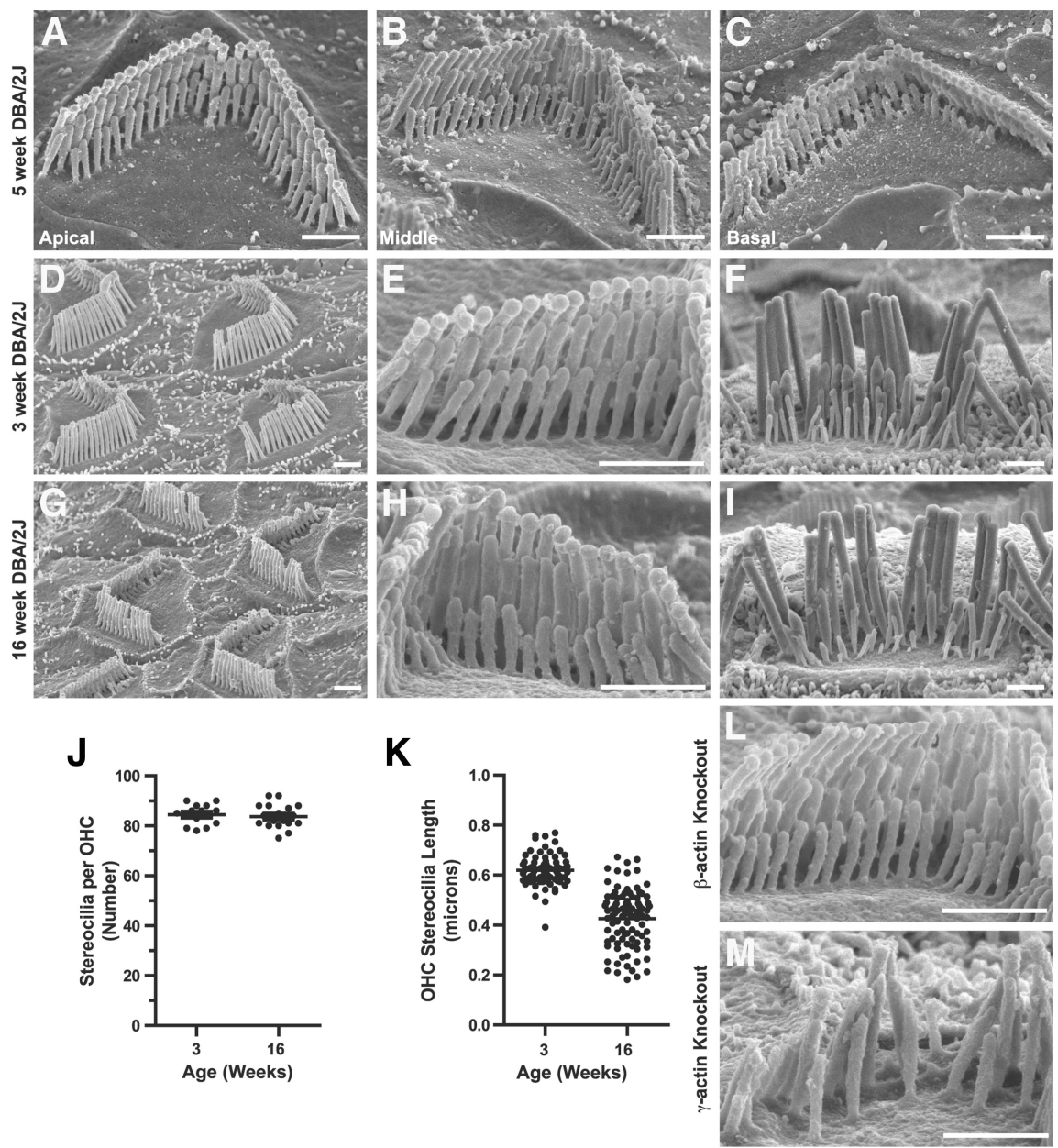

Figure 2. The shorter rows of DBA/2J (FsCn2 $\left.2^{R 109 H / R 109 H}\right)$ stereocilia shorten during aging. A-C, Scanning electron microscopy was used to image stereocilia from the apical $(\boldsymbol{A})$, middle $(\boldsymbol{B})$, or basal turn $(\boldsymbol{C})$ of 5 -week-old DBA/2J mice. Shortening of stereocilia in rows 2 and 3 of the bundle is evident with a basal to apical gradient of severity. $\boldsymbol{D}-\boldsymbol{F}$, In the middle turn of cochlea from 3-week-old mice $\mathrm{OHC}(\boldsymbol{D}, \boldsymbol{E})$ and IHC $(\boldsymbol{F})$ stereocilia have a normal appearance. $\boldsymbol{G}-\boldsymbol{I}$, At 16 weeks of age, $\mathrm{OHC}(\boldsymbol{G}, \boldsymbol{H})$ and IHC $(\boldsymbol{I})$ stereocilia in rows 2 and 3 have irregular lengths. $\boldsymbol{J}, \boldsymbol{K}$, The average number $(\boldsymbol{J})$ of $\mathrm{OHC}$ stereocilia from the middle turn of 3 - or 16-week-old DBA/2J mice is similar, whereas the average length $(\boldsymbol{K})$ of row 3 stereocilia is decreased at 16 weeks of age. Each dot is the average value for one cell. $\boldsymbol{L}, \boldsymbol{M}$, At 16 weeks of age, $\beta$-actin knock-out (Actb ${ }^{\text {flox fllox }}$ Atoh 1 -cre) stereocilia ( $\boldsymbol{L}$ ) have a similar phenotype with shortening of $\mathrm{OHC}$ stereocilia in rows 2 and 3 , whereas $\gamma$-actin knock-out (Actg $7^{\text {flox/flox }}$ Atoh 1-cre) stereocilia $(\boldsymbol{M})$ have a distinct morphology where individual stereocilia are missing. Both actin knock-out lines are on the B6 background. Scale bars, $1 \mu \mathrm{m}$.

\section{Fascin-2 p.R109H binds actin but does not efficiently bundle actin filaments}

To better understand the role of fascin-2 in maintaining stereocilia length, we sought to identify biochemical changes in fascin- 2 resulting from the $\mathrm{R} 109 \mathrm{H}$ substitution. Mouse fascin-2 shares $56 \%$ amino acid identity and $73 \%$ similarity with mouse fascin- 1 , which is a monomeric protein with two actin-binding sites that together account for its ability to crosslink actin filaments (Sedeh et al., 2010; Jansen et al., 2011). As the fascin-1 R109 residue was previously implicated in actin binding (Jansen et al., 2011), we reasoned the $\mathrm{R} 109 \mathrm{H}$ mutation of fascin-2 might disrupt one of the actin binding sites. We purified recombinant, baculovirus-expressed Flag-tagged fascin-2 and fascin- 2 p.R109H proteins by Flag-affinity chromatography (Fig. 3A). Each protein bound to filamentous actin (F-actin) with a similar affinity (fascin-2 $\mathrm{Kd}=4.95 \pm 1.05 \mu \mathrm{M}$ and fascin-2 p.R109H Kd $=5.97 \pm 2.17 \mu \mathrm{M}$ ) as measured by a highspeed cosedimentation assay where $\mathrm{F}$-actin is pelleted along with any binding proteins (Fig. 3B). To determine whether fascin-2 p.R109H retained the ability to crosslink actin filaments, we used a low-speed cosedimentation assay where the centrifugation force was too low to pellet F-actin unless it was assembled into multifilament arrays. In this experiment, actin was shifted to the pellet fraction by fascin- 2 but not by fascin-2 p.R109H (Fig. 3C), demonstrating that the R109H substitution prevents efficient actin crosslinking. Because fascin-2 p.R109H can bind but not bundle actin filaments, we conclude that R109H substitution ablates one of the two actin-binding sites. To determine whether this biochemical defect altered fascin-2 localization in stereocilia we used a dye-conjugated polyclonal antibody to fascin-2 to immunostain IHC and $\mathrm{OHC}$ stereocilia from control B6 mice or B6.D2-Fscn $2^{R 109 H}$ mice, which express fascin-2 p.R109H on an otherwise B6 background (Fig. 3D). Consistent with a previous report, fascin-2 localizes along the length of stereocilia with particular enrichment above the region of the stereocilia taper (Shin et al., 2010). Fascin-2 p.R109H has a similar localization pattern (Fig. 3D); however, the level is reduced compared with control with the ratio of fascin-2 to $\gamma$-actin immunofluorescence reduced in B6.D2Fscn2 $2^{R 109 H}$ stereocilia to $35 \pm 18 \%$ that of B6 stereocilia $( \pm$ SD, $n=62$ B6 and 57 B6.D2-Fscn2 $\left.{ }^{R 109 H} \mathrm{IHCs}\right)$.

\section{Fascin-2 does not preferentially interact with $\boldsymbol{\beta}$-actin}

Because mice expressing fascin-2 p.R109H or lacking $\beta$-actin have similar phenotypes, we considered whether fascin-2 preferentially bound to $\beta$-actin over $\gamma$-actin to form a functional complex. To this end, we used the high speed cosedimentation assay to measure the affinity of fascin-2 for a mixture of $85 \%$ $\beta$-actin and $15 \% \gamma$-actin purified from platelets compared with recombinant $\gamma$-actin expressed by baculovirus in insect cells (Fig. 4A). Fascin-2 and the constitutively active phosphoresistant fascin-2 S39A bound to platelet actin with an apparent Kds of $4.15 \pm 0.49 \mu \mathrm{M}$ and $3.91 \pm 0.37 \mu \mathrm{M}$, which are similar to the affinity of fascin-2 binding to $\alpha$-skeletal actin. Likewise, fascin-2 bound to $\gamma$-actin with a Kd of $6.17 \pm 0.71$ $\mu \mathrm{M}$, a difference that was not statistically significant (Fig. $4 B, C)$.

We also wanted to test for preferential association of fascin-2 and $\beta$-actin in a relevant cellular context. We compared fascin-2 localization in IHC stereocilia after stopping expression of $\beta$-actin in adult mice through cre-mediated excision of the Actb gene. We reasoned that if fascin-2 preferentially interacts with $\beta$-actin, then fascin- 2 would be lost from stereocilia concurrently with the loss of $\beta$-actin. Fascin- 2 and $\beta$-actin colocalized along the length and extending to the tip of control IHC stereocilia (Fig. $4 D$ ). In the conditional $\beta$-actin knock-out, fascin- 2 was retained at stereocilia tips even as $\beta$-actin was lost from this region (Fig. $4 D$ ) demonstrating that fascin- 2 does not depend on $\beta$-actin for normal localization. Consistent with our previous report, both 

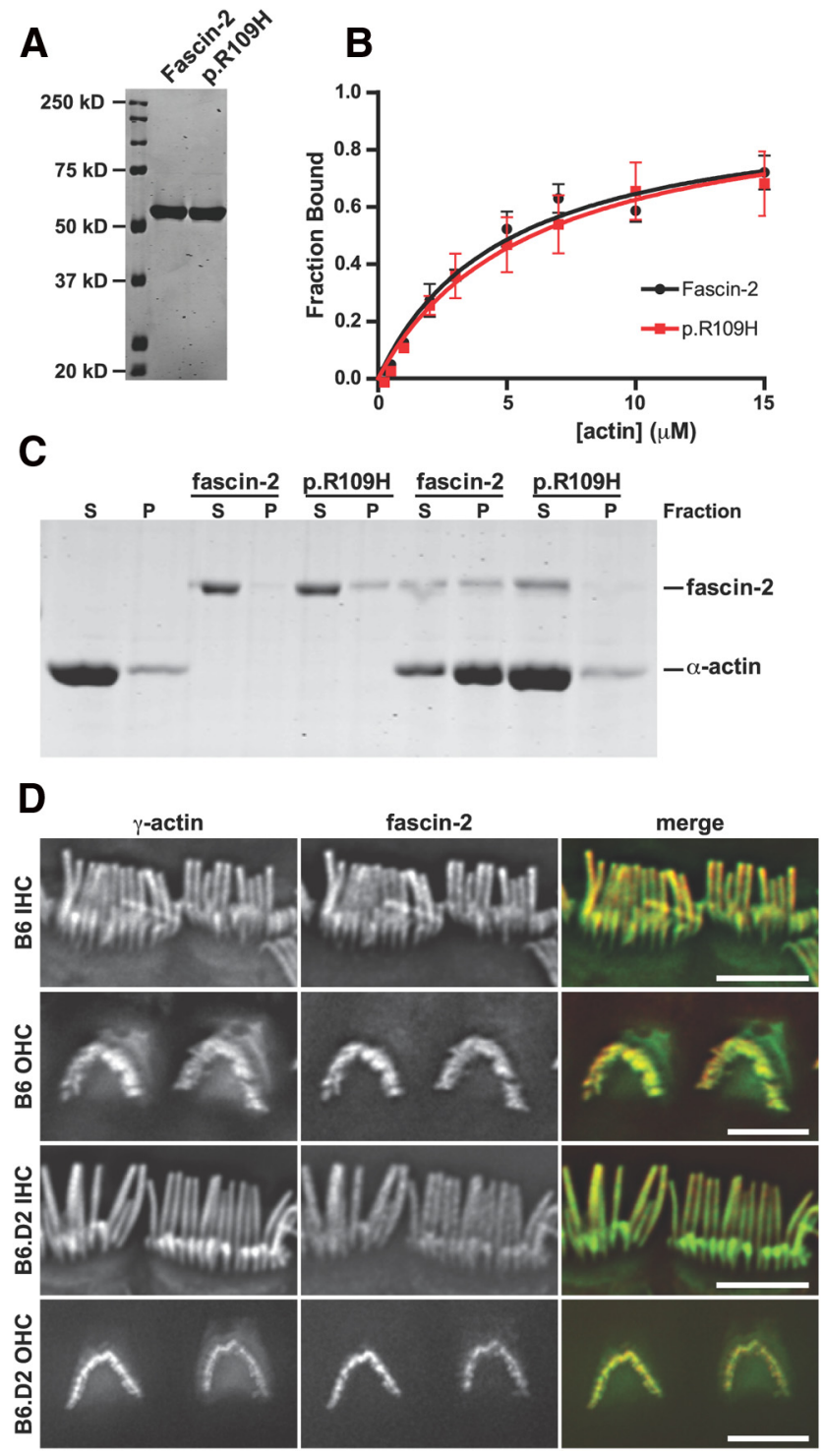

Figure 3. Fascin-2 p.R109H binds actin but inefficiently crosslinks actin filaments. $\boldsymbol{A}$, Mouse fascin-2 or fascin-2 p.R109H proteins with $\mathrm{N}$-terminal Flag tags were expressed in insect cells using a baculovirus expression system, purified by Flag affinity chromatography, and stained with Coomassie blue. $\boldsymbol{B}$, Binding curve from high-speed cosedimentation analysis of $750 \mathrm{~nm}$ fascin-2 or fascin-2 p.R109H mixed with varying concentrations of $\alpha$-skeletal F-actin and the fraction bound was determined. C, Low-speed cosedimentation analysis showing that fascin-2 binding shifts actin from the supernatant to the pellet fraction, whereas actin remains in the supernatant fraction following fascin-2 p.R109H binding. $500 \mathrm{~nm}$ Flag-fascin-2 or Flag-fascin-2 p.R109H was mixed with $5 \mu \mathrm{m} \alpha$-skeletal F-actin. $\boldsymbol{D}$, The localization of fascin-2 and fascin-2 p.R109H was assessed in $\mathrm{HCS}$ and $\mathrm{OHCs}$ by comparing immunolocalization patterns in control B6 mice to age matched B6.D2-Fscn2 ${ }^{R 109 H}$ mice, which express fascin-2 p.R109H on a B6 background. The localization pattern was similar in both strains, but the fascin-2 p.R109H was detected at a lower intensity. Scale bars, $5 \mu \mathrm{m}$.

fascin- 2 and $\beta$-actin are retained along the stereocilia length where actin turnover is very slow (Zhang et al., 2012).

Finally, we considered whether Fscn 2 expression is unexpectedly decreased in Actb knock-outs, perhaps due to the close genomic proximity of $F s c n 2$ to Actg1 and Fscn 1 to Actb, which are, respectively, separated by 13 and $53.6 \mathrm{~kb}$ in mice (Tubb et al., 2000; Shin et al., 2010). In mouse embryonic fibroblasts (MEFs) derived from tamoxifen inducible Actb or Actg1 knock-out mice (Bunnell et al., 2011) we noted the opposite effect, where after Actb knock-out fascin-2 protein and transcript levels increased
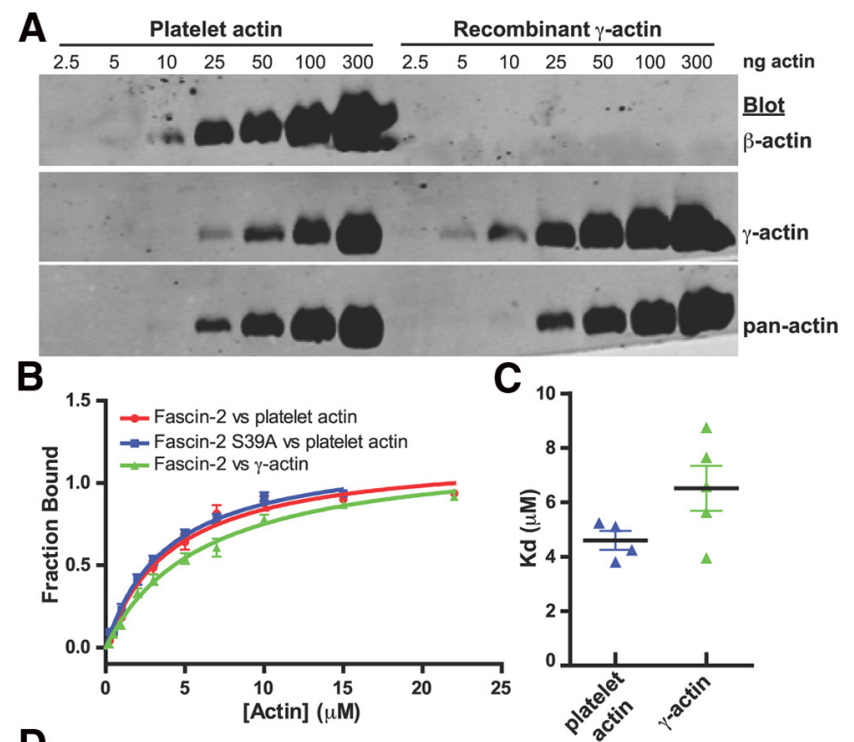

D

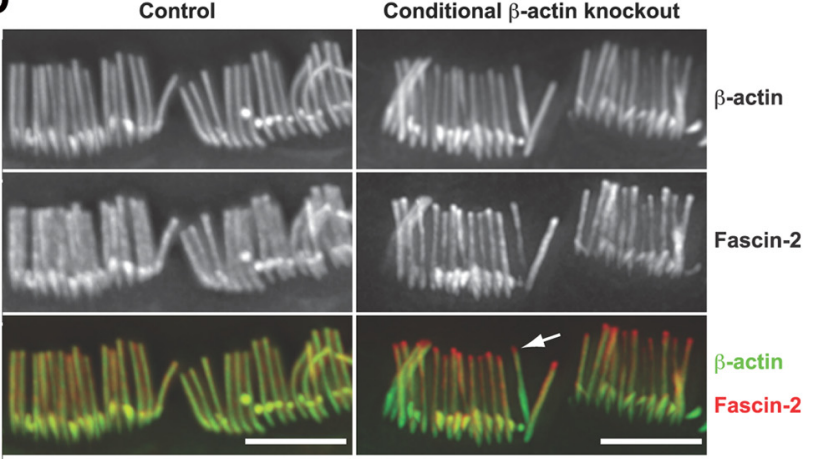

Figure 4. Fascin-2 binds $\beta$-actin and $\gamma$-actin with similar affinities and does not depend on $\beta$-actin for localization. $A$, Immunoblot analysis to compare actin purified from platelets with recombinant $\gamma$-actin expressed in insect cells. The indicated concentrations of each actin were probed with antibodies to $\beta$-actin, $\gamma$-actin, or pan-actin. $\boldsymbol{B}$, Binding curves from high-speed cosedimentation analysis of $750 \mathrm{~nm}$ fascin-2 mixed with varying concentrations of platelet actin or $\gamma$-actin. $C$, Kd values calculated from binding curves; differences are not statistically significant $(p=0.09)$. $\boldsymbol{D}$, Fascin- 2 and $\beta$-actin were immunolocalized in inner hair cell stereocilia from control mice ( $A c t b^{f l o x}$ fflox $)$ or from mice where $\beta$-actin was knocked out during adulthood (Actb flox/flox with the CAG-cre/ESR1 transgene). $\beta$-Actin was lost from the tips of knock-out stereocilia, while fascin-2 remained in this region. Scale bars, $5 \mu \mathrm{m}$.

(Fig. $5 A, B$ ). In cochlear tissue we did not detect any change in fascin-2 protein levels following knockout of either Actb or Actg1 (Fig. 5C). These data suggest that Fscn2 and Actg1 can be coordinately regulated in some cellular contexts, but that decreased fascin gene expression does not account for the similar phenotypes observed in $\beta$-actin knock-out and $F s c n 2^{R 109 H}$ stereocilia. Together, these three lines of evidence indicate that fascin-2 and $\beta$-actin do not specifically interact in hair cells on a biochemical or regulatory level to maintain stereocilia length.

Fscn $2^{\mathrm{R} 109 \mathrm{H}} \boldsymbol{\beta}$-actin knock-out double-mutant mice have a compound phenotype

Because fascin- 2 and $\beta$-actin do not appear to form an exclusive complex yet mutations in either results in high-frequency hearing loss and shortening of row 2 and row 3 stereocilia, we hypothesized that each protein must influence stereocilia actin dynamics through different mechanisms. To test this idea, we compared auditory function and stereocilia morphology in hair cellspecific $\beta$-actin knock-out mice that also express fascin-2 p.R109H $\left(F s c n 2^{R 109 H / R 109 H}\right.$ Actb ${ }^{\text {flox/flox }}$ Atoh1-cre double- 

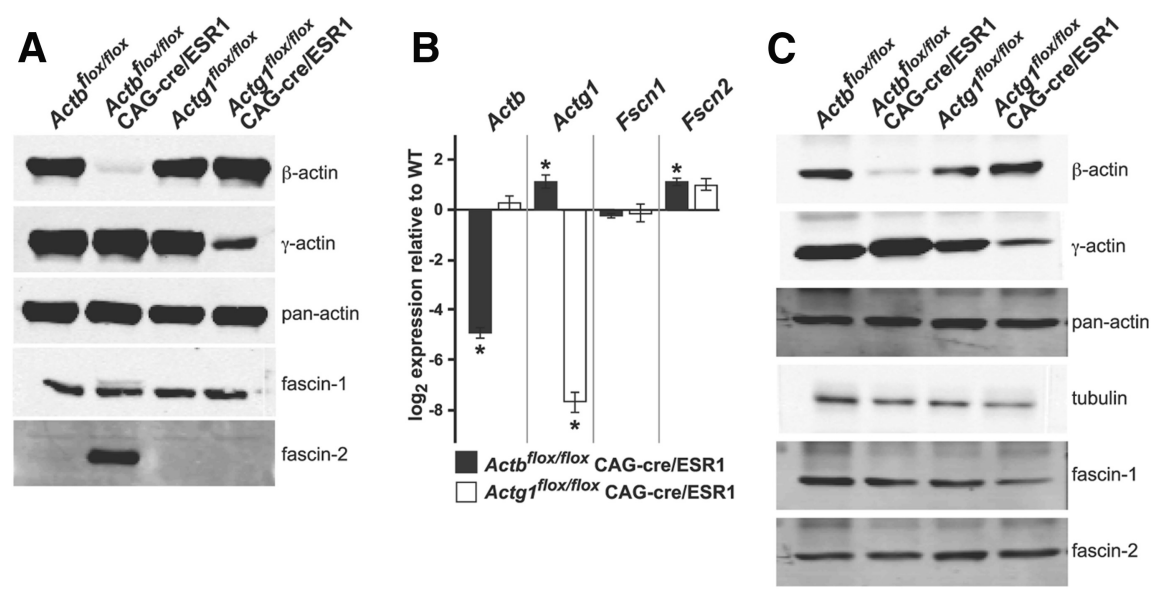

Figure 5. Analysis of coregulation of actins and fascins. $A, B$, Actin and fascin protein and transcript levels in actin knock-out MEFs were analyzed by immunoblotting $(\boldsymbol{A})$ or qPCR $(\boldsymbol{B})$. Total levels of actin protein were maintained in both $\beta$-actin and $\gamma$-actin knock-out MEFs. Fascin- 1 levels also remained constant while fascin- 2 was detectable only in $\beta$-actin knock-outs ( $\boldsymbol{A}$ ). Correspondingly, Fscn2 transcript was significantly increased in Actb knock-out MEFs $(p<0.05)(\boldsymbol{B})$. C, Protein levels were assessed in cochlear extracts by immunoblot analysis with the indicated antibodies. Fascin-2 was detected in cochlear tissue from all mouse lines and levels were not markedly altered by either $\beta$-actin or $\gamma$-actin knockout.

mutant mice) to that of single-mutant mice $\left(F s c n 2^{R 109 H / R 109 H}\right.$ or Actb flox/flox Atoh1-cre), each on a congenic B6 genetic background. We found that fascin-2 p.R109H on the B6 background resulted in a slower progression of hearing loss compared with the DBA/2J background; however, the patterns of hearing loss and stereocilia pathology were otherwise similar. In particular, ABRs demonstrated that hearing impairment started with high-frequency hearing loss evident at $16 \mathrm{kHz}$ and higher at 16 weeks of age, and was progressive, resulting in both larger threshold shifts and lowfrequency hearing loss as mice aged to 24 weeks (Fig. 6A). Correspondingly, in the middle turn of the cochlea $\mathrm{OHC}$ stereocilia morphology appeared normal at 6 weeks of age, but at 16 and 24 weeks of age stereocilia shortening and height variability was progressively evident in rows 2 and 3 of the bundle (Fig. 6B-D). Interestingly, this timeline of pathology is very similar to our previous observations of $\beta$-actin knock-out mice (Perrin et al., 2010). Double-mutant mice homozygous for both $F s c n 2^{R 109 H}$ and $A c t b^{f l o x}$ and carrying the Atoh1-cre transgene had markedly accelerated hearing loss compared with either single mutant with larger threshold shifts affecting more sound frequencies at younger ages (Fig. $6 E$ ). Stereocilia in the second and third rows of $\mathrm{OHC}$ bundles from double-mutant mice had irregular lengths at 12 weeks of age (Fig. $6 F$ ) and were similar in appearance to single mutants at 16 weeks of age. Thus, pathology in fascin- $2 \mathrm{pR} 109 \mathrm{H}$ $\beta$-actin knock-out double mutants is phenotypically similar to each single mutant but with an earlier onset demonstrating synergistic function of fascin-2 and $\beta$-actin.

\section{Discussion}

We describe a stereocilia maintenance defect that is phenotypically similar whether arising from $\beta$-actin knockout or expression of a mutant fascin-2 protein. This phenotype is characterized by progressive hearing loss that initiates in the high-frequency sound range, shortening of rows 2 and 3 of the stereocilia bundle and dependence on homozygosity of the $C d h 23^{a h l}$ allele. The mutant fascin-2 p.R109H protein inefficiently crosslinks actin and is present at reduced levels in stereocilia. Although $\beta$-actin knockout and fascin-2 p.R109H mutant stereocilia develop a similar pathology that is distinct from that of $\gamma$-actin knock-outs, fascin- 2 does not bind $\beta$-actin with higher affinity than $\gamma$-actin or depend on $\beta$-actin for normal localization in stereocilia. Consistent with each protein carrying out different functions in the same repair pathway, the phenotype has an earlier onset and more severe progression in double-mutant mice that lack $\beta$-actin and express fascin-2 p.R109H. These data, together with our current model of stereocilia actin dynamics, suggest that fascin-2 and $\beta$-actin cooperate to modulate actin disassembly at stereocilia tips.

Although stereocilia actin was initially proposed to turnover in several hours by a treadmilling mechanism (Schneider et al., 2002; Rzadzinska et al., 2004), we recently published data supporting a model where actin filaments within stereocilia are very stable (Zhang et al., 2012). Consistent with this view, after conditional knockout of either $\beta$-actin or $\gamma$-actin in adult stereocilia, the ablated isoform remains in stereocilia shafts even several months after gene knockout. Likewise, multi-isotope imaging mass spectrometry demonstrated that protein turnover is very slow in stereocilia shafts, with a significant fraction of protein having a months-long half-life. Both of these approaches also identified a small region of $\sim 0.5 \mu \mathrm{m}$ at stereocilia tips that has much faster turnover. Thus, the F-actin in stereocilia is largely static though with ongoing remodeling at the filament barbed ends near stereocilia tips (Zhang et al., 2012).

Fascin-2 may slow stereocilia actin turnover as multiple lines of evidence demonstrate that actin dynamics are regulated by filament crosslinking. Most recently, purified fascin-1 was shown to slow depolymerization of actin filaments using purified components and in vitro assays (Breitsprecher et al., 2011; Schmoller et al., 2011). In vivo, fascin is required for Drosophila melanogaster bristle morphogenesis to properly regulate the assembly of actin bundles. In this system, fascin stabilizes nascent actin structures preventing their depolymerization (Tilney et al., 2003). If fascin-2 crosslinks slow actin turnover in stereocilia, then the $\mathrm{R} 109 \mathrm{H}$ mutant, which inefficiently crosslinks actin, may offer decreased protection against actin filament depolymerization and allow monomer loss at the dynamic regions found at stereocilia tips.

$\beta$-Actin may contribute to stereocilia length maintenance through a number of different mechanisms. Recombinant $\beta$-actin has been shown to have different polymerization properties than recombinant $\gamma$-actin with faster polymerization and depolymerization kinetics under calcium bound conditions (Bergeron et al., 2010). Loss of $\beta$-actin from stereocilia may therefore alter the balance of assembly and disassembly in the dynamic tip zone of stereocilia. It also remains likely that some actin binding proteins depend on $\beta$-actin for normal activity. This mechanism seems particularly plausible given recent highresolution structures of filamentous actin demonstrating that the $N$ termini of actin monomers where $\beta$-actin and $\gamma$-actin sequences differ are exposed to solvent (Oda et al., 2009; Fujii et al., 2010). Although fascin- 2 binds $\beta$-actin and $\gamma$-actin with similar affinities, there are many other candidate actin-binding proteins in stereocilia. For example, unconventional myosins, such as myosin IIIa, myosin 15a, and myosin 7 a that regulate stereocilia length (Belyantseva et al., 2005; Prosser et al., 2008; Salles et al., 
2009) may move with different kinetics on each actin isoform. The capping protein twinfillin is another intriguing candidate because it localizes only to the tips of row 2 and 3 stereocilia, the same stereocilia that shorten in $\beta$-actin knock-outs (Peng et al., 2009; Rzadzinska et al., 2009).

Although the mechanism of $\beta$-actindependent stereocilia length regulation remains under investigation, it is increasingly clear that $\beta$-actin and $\gamma$-actin isoforms, although 99\% identical in amino acid sequence, have distinct functions in mature hair cells. Consistent with this view, $\beta$-actin and $\gamma$-actin knock-outs developed different forms of progressive hearing loss and stereocilia pathology (Belyantseva et al., 2009; Perrin et al., 2010). In addition, $C d h 23^{+}$suppresses hearing loss in hair cell-specific $\beta$-actin knock-out mice (Fig. 1), whereas it did not prevent hearing loss or stereocilia degradation because of the loss of $\gamma$-actin (Perrin et al., 2010). The differing functional relationship of $\beta$-actin and $\gamma$-actin to the stereocilia tip-link protein cadherin-23 suggests that $\beta$-actin is required in stereocilia, whereas $\gamma$-actin may be important for a more general cellular function. Interestingly, each actin isoform is dispensable for stereocilia development as hair cells lacking either $\beta$-actin or $\gamma$-actin form morphologically and functionally normal stereocilia (Perrin et al., 2010), a point reinforced by Cdh $23^{+}$suppression of hearing loss in $\beta$-actin knock-outs. The differing requirements for actin isoforms in developing and mature stereocilia may reflect age-related changes in cell fitness or modification of actin dynamics upon stereocilia maturation.

This study also adds to a growing body of evidence suggesting that mechanotransduction regulates actin dynamics to maintain the staircase morphology of stereocilia bundles. Importantly, rows 2 and 3 of the bundle house the transduction channel as evidenced by high-speed imaging of calcium influx (Beurg et al., 2009). These same rows of stereocilia shorten when tip links are lost after early postnatal knock-out of sans protein (Caberlotto et al., 2011a,b). Similarly, loss of the mechanotransduction cofactor TMHS decreases tip-link formation and channel activity and causes defects in length regulation of stereocilia in rows 2 and 3 of the bundle (Xiong et al., 2012). Such a correlation raises interesting questions about how tip-link tension and the influx of ions after channel activation modify actin dynamics.

A connection between tip links, channel activity, and stereocilia maintenance may shed light on why progressive hearing loss phenotypes in inbred mouse lines often depend on homozygosity for the $C d h 23^{a h l}$ allele. The alternatively spliced $C d h 23^{a h l}$ transcript encodes a protein lacking 43 aa comprising part of the second and third ectodomains (Noben-Trauth et al., 2003). This deletion may decrease the fraction of stereo-
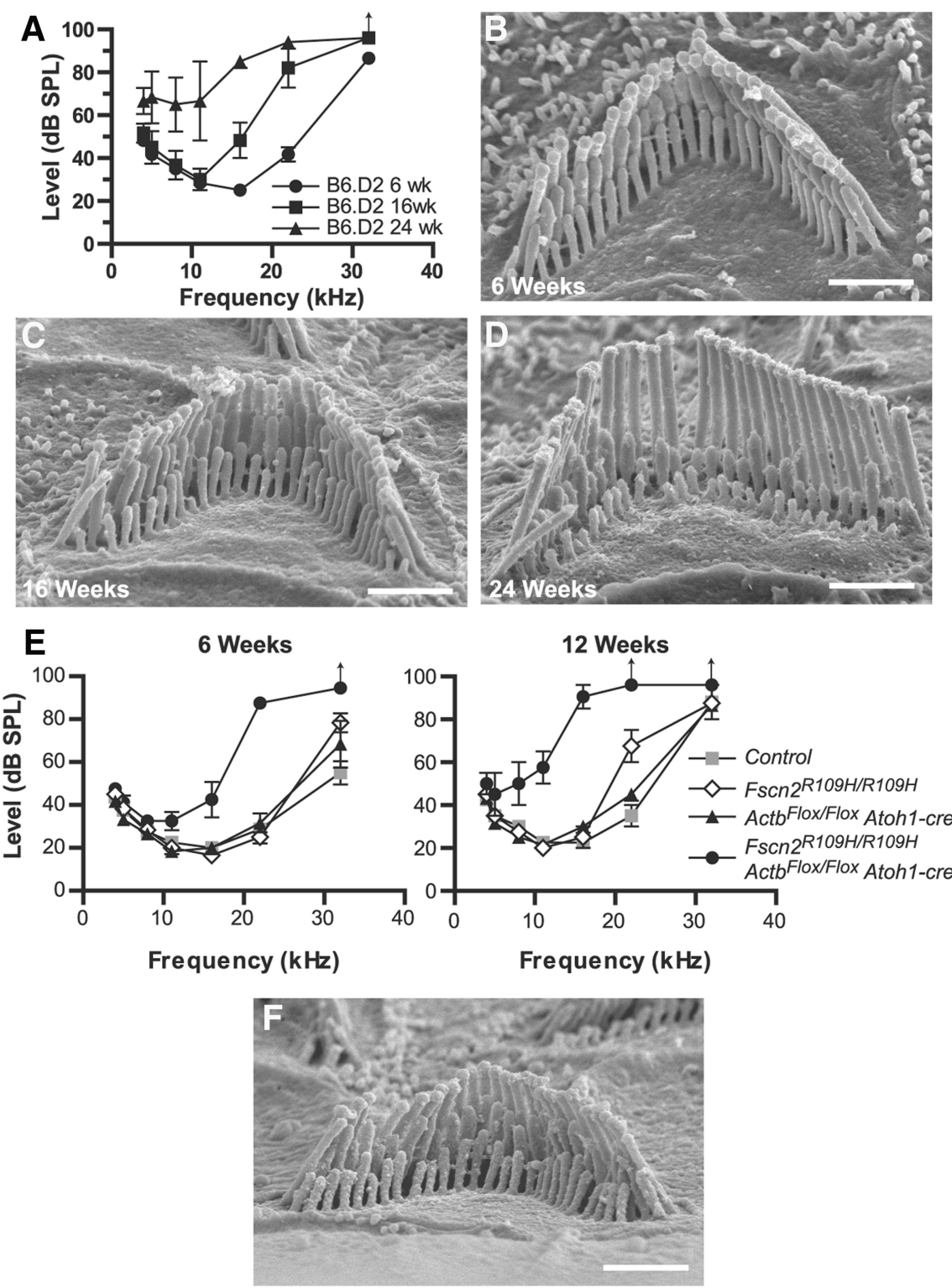

Figure 6. Double-mutant mice expressing fascin-2 p.R109H and lacking $\beta$-actin have a more severe phenotype. $\boldsymbol{A}-\boldsymbol{D}$, The effect of fascin-2p.R109H expression was assessed on a B6 background by measuring $A B R$ thresholds $(A)$ and by SEM of middle turn ompared with DBA/2J mice, the phenotype is similar but with slower onset and progression. Double-mutant mice expressing fascin-2 p.R109H and lacking $\beta$-actin (Fscn2 ${ }^{R 109 H / R 109 H}$ Actb ${ }^{\text {flox/flox }}$ Atoh1-cre) were compared with each single mutant (Fscn2 ${ }^{R 109 H / R 109 H}$ or Actb flox/flox Atoh1-cre) and control mice, all on a congenic B6 background. E, F, ABR thresholds were measured at 6 and 12 weeks of age $(\boldsymbol{E})$ and morphology of the double mutant was assessed by SEM at 12 weeks of age $(\boldsymbol{F})$. Scale bars, $1 \mu \mathrm{m}$.

cilia with functional tip links if the resulting cadherin-23 protein is less stable, binds inefficiently to protocadherin 15 , or is poorly trafficked to stereocilia tips. Downstream of tip link defects, stereocilia must be stabilized in the absence of mechanotransduction activity until tip links are repaired. In this view, $C d h 23^{a h l}$ mouse lines, such as B6, are sensitized strains that are valuable tools for discovering and characterizing stereocilia maintenance mechanisms.

$\beta$-Actin and fascin-2 are components of such a pathway, and in this study we characterized their functional relationship in mature stereocilia. Each of these abundant cytoskeletal proteins contributes to stereocilia length regulation through a common pathway that is genetically linked to the tip-link component cadherin-23. These components, along with other as of yet un- 
identified actin regulatory proteins, are essential for maintaining stereocilia architecture and function during aging.

\section{References}

Belyantseva IA, Boger ET, Naz S, Frolenkov GI, Sellers JR, Ahmed ZM, Griffith AJ, Friedman TB (2005) Myosin-XVa is required for tip localization of whirlin and differential elongation of hair-cell stereocilia. Nat Cell Biol 7:148-156. CrossRef Medline

Belyantseva IA, Perrin BJ, Sonnemann KJ, Zhu M, Stepanyan R, McGee J, Frolenkov GI, Walsh EJ, Friderici KH, Friedman TB, Ervasti JM (2009) Gamma-actin is required for cytoskeletal maintenance but not development. Proc Natl Acad Sci U S A 106:9703-9708. CrossRef Medline

Bergeron SE, Zhu M, Thiem SM, Friderici KH, Rubenstein PA (2010) Iondependent polymerization differences between mammalian beta- and gamma-nonmuscle actin isoforms. J Biol Chem 285:16087-16095. CrossRef Medline

Beurg M, Fettiplace R, Nam JH, Ricci AJ (2009) Localization of inner hair cell mechanotransducer channels using high-speed calcium imaging. Nat Neurosci 12:553-558. CrossRef Medline

Breitsprecher D, Koestler SA, Chizhov I, Nemethova M, Mueller J, Goode BL, Small JV, Rottner K, Faix J (2011) Cofilin cooperates with fascin to disassemble filopodial actin filaments. J Cell Sci 124:3305-3318. CrossRef Medline

Bunnell TM, Burbach BJ, Shimizu Y, Ervasti JM (2011) beta-actin specifically controls cell growth, migration, and the G-actin pool. Mol Biol Cell 22:4047-4058. CrossRef Medline

Caberlotto E, Michel V, de Monvel JB, Petit C (2011a) Coupling of the mechanotransduction machinery and F-actin polymerization in the cochlear hair bundles. Bioarchitecture 1:169-174. CrossRef Medline

Caberlotto E, Michel V, Foucher I, Bahloul A, Goodyear RJ, Pepermans E, Michalski N, Perfettini I, Alegria-Prévot O, Chardenoux S, Do Cruzeiro M, Hardelin JP, Richardson GP, Avan P, Weil D, Petit C (2011b) Usher type $1 \mathrm{G}$-protein sans is a critical component of the tip-link complex, a structure controlling actin polymerization in stereocilia. Proc Natl Acad Sci U S A 108:5825-5830. CrossRef Medline

Davis RC, Schadt EE, Smith DJ, Hsieh EW, Cervino AC, van Nas A, Rosales M, Doss S, Meng H, Allayee H, Lusis AJ (2005) A genome-wide set of congenic mouse strains derived from DBA/2J on a C57BL/6J background. Genomics 86:259-270. CrossRef Medline

Fujii T, Iwane AH, Yanagida T, Namba K (2010) Direct visualization of secondary structures of F-actin by electron cryomicroscopy. Nature 467: 724-728. CrossRef Medline

Hayashi S, McMahon AP (2002) Efficient recombination in diverse tissues by a tamoxifen-inducible form of Cre: a tool for temporally regulated gene activation/inactivation in the mouse. Dev Biol 244:305-318. CrossRef Medline

Jansen S, Collins A, Yang C, Rebowski G, Svitkina T, Dominguez R (2011) Mechanism of actin filament bundling by fascin. J Biol Chem 286:3008730096. CrossRef Medline

Johnson KR, Longo-Guess C, Gagnon LH, Yu H, Zheng QY (2008) A locus on distal chromosome 11 (ahl8) and its interaction with Cdh23 ahl underlie the early onset, age-related hearing loss of DBA/2J mice. Genomics 92:219-225. CrossRef Medline

Kazmierczak P, Sakaguchi H, Tokita J, Wilson-Kubalek EM, Milligan RA, Müller U, Kachar B (2007) Cadherin 23 and protocadherin 15 interact to form tip-link filaments in sensory hair cells. Nature 449:87-91. CrossRef Medline

Keithley EM, Canto C, Zheng QY, Fischel-Ghodsian N, Johnson KR (2004) Age-related hearing loss and the ahl locus in mice. Hear Res 188:21-28. CrossRef Medline

Lin-Jones J, Burnside B (2007) Retina-specific protein fascin 2 is an actin cross-linker associated with actin bundles in photoreceptor inner segments and calycal processes. Invest Ophthalmol Vis Sci 48:1380-1388. CrossRef Medline

Loomis PA, Zheng L, Sekerková G, Changyaleket B, Mugnaini E, Bartles JR (2003) Espin cross-links cause the elongation of microvillus-type parallel actin bundles in vivo. J Cell Biol 163:1045-1055. CrossRef Medline

Matei V, Pauley S, Kaing S, Rowitch D, Beisel KW, Morris K, Feng F, Jones K,
Lee J, Fritzsch B (2005) Smaller inner ear sensory epithelia in Neurog 1 null mice are related to earlier hair cell cycle exit. Dev Dyn 234:633-650. CrossRef Medline

Noben-Trauth K, Johnson KR (2009) Inheritance patterns of progressive hearing loss in laboratory strains of mice. Brain Res 1277:42-51. CrossRef Medline

Noben-Trauth K, Zheng QY, Johnson KR (2003) Association of cadherin 23 with polygenic inheritance and genetic modification of sensorineural hearing loss. Nat Genet 35:21-23. CrossRef Medline

Oda T, Iwasa M, Aihara T, Maéda Y, Narita A (2009) The nature of the globular- to fibrous-actin transition. Nature 457:441-445. CrossRef Medline

Peng AW, Belyantseva IA, Hsu PD, Friedman TB, Heller S (2009) Twinfilin 2 regulates actin filament lengths in cochlear stereocilia. J Neurosci 29: 15083-15088. CrossRef Medline

Perrin BJ, Sonnemann KJ, Ervasti JM (2010) $\beta$-Actin and $\gamma$-actin are each dispensable for auditory hair cell development but required for stereocilia maintenance. PLoS Genetics 6:e1001158. CrossRef Medline

Prochniewicz E, Thomas DD (1999) Differences in structural dynamics of muscle and yeast actin accompany differences in functional interactions with myosin. Biochemistry 38:14860-14867. CrossRef Medline

Prosser HM, Rzadzinska AK, Steel KP, Bradley A (2008) Mosaic complementation demonstrates a regulatory role for myosin VIIa in actin dynamics of stereocilia. Mol Cell Biol 28:1702-1712. CrossRef Medline

Rzadzinska AK, Schneider ME, Davies C, Riordan GP, Kachar B (2004) An actin molecular treadmill and myosins maintain stereocilia functional architecture and self-renewal. J Cell Biol 164:887-897. CrossRef Medline

Rzadzinska AK, Nevalainen EM, Prosser HM, Lappalainen P, Steel KP (2009) MyosinVIIa interacts with Twinfilin-2 at the tips of mechanosensory stereocilia in the inner ear. PLoS One 4:e7097. CrossRef Medline

Salles FT, Merritt RC Jr, Manor U, Dougherty GW, Sousa AD, Moore JE, Yengo CM, Dosé AC, Kachar B (2009) Myosin IIIa boosts elongation of stereocilia by transporting espin 1 to the plus ends of actin filaments. Nat Cell Biol 11:443-450. CrossRef Medline

Schmoller KM, Semmrich C, Bausch AR (2011) Slow down of actin depolymerization by cross-linking molecules. J Struct Biol 173:350-357. CrossRef Medline

Schneider ME, Belyantseva IA, Azevedo RB, Kachar B (2002) Rapid renewal of auditory hair bundles. Nature 418:837-838. CrossRef Medline

Sedeh RS, Fedorov AA, Fedorov EV, Ono S, Matsumura F, Almo SC, Bathe M (2010) Structure, evolutionary conservation, and conformational dynamics of Homo sapiens Fascin-1, an F-actin crosslinking protein. J Mol Biol 400:589-604. CrossRef Medline

Shin JB, Longo-Guess CM, Gagnon LH, Saylor KW, Dumont RA, Spinelli KJ, Pagana JM, Wilmarth PA, David LL, Gillespie PG, Johnson KR (2010) The $\mathrm{R} 109 \mathrm{H}$ variant of fascin-2, a developmentally regulated actin crosslinker in hair-cell stereocilia, underlies early onset hearing loss of DBA/2J mice. J Neurosci 30:9683-9694. CrossRef Medline

Shin JB, Krey JF, Hassan A, Metlagel Z, Tauscher AN, Pagana JM, Sherman NE, Jeffery ED, Spinelli KJ, Zhao H, Wilmarth PA, Choi D, David LL, Auer M, Barr-Gillespie PG (2013) Molecular architecture of the chick vestibular hair bundle. Nat Neurosci 16:365-374. CrossRef Medline

Tilney LG, Connelly PS, Ruggiero L, Vranich KA, Guild GM (2003) Actin filament turnover regulated by cross-linking accounts for the size, shape, location, and number of actin bundles in Drosophila bristles. Mol Biol Cell 14:3953-3966. CrossRef Medline

Tubb BE, Bardien-Kruger S, Kashork CD, Shaffer LG, Ramagli LS, Xu J, Siciliano MJ, Bryan J (2000) Characterization of human retinal fascin gene (FSCN2) at 17q25: close physical linkage of fascin and cytoplasmic actin genes. Genomics 65:146-156. CrossRef Medline

Xiong W, Grillet N, Elledge HM, Wagner TF, Zhao B, Johnson KR, Kazmierczak P, Müller U (2012) TMHS is an integral component of the mechanotransduction machinery of cochlear hair cells. Cell 151:1283-1295. CrossRef Medline

Zhang DS, Piazza V, Perrin BJ, Rzadzinska AK, Poczatek JC, Wang M, Prosser HM, Ervasti JM, Corey DP, Lechene CP (2012) Multi-isotope imaging mass spectrometry reveals slow protein turnover in hair-cell stereocilia. Nature 481:520-524. CrossRef Medline 